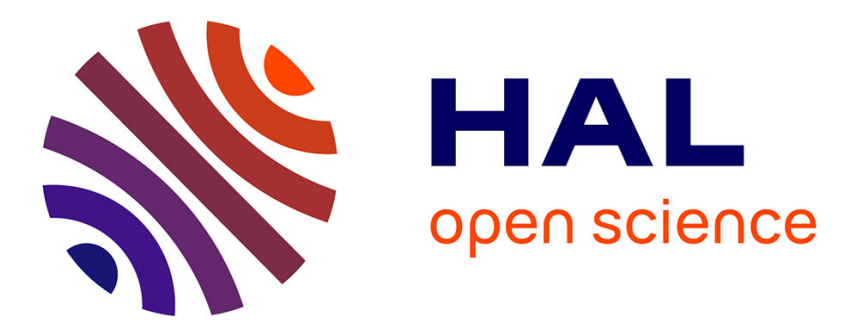

\title{
Social Mapping for Communal Sensemaking: The Case of Development Informatics Researchers in South Africa
}

\author{
Judy Van Biljon, Mario Marais
}

\section{To cite this version:}

Judy Van Biljon, Mario Marais. Social Mapping for Communal Sensemaking: The Case of Development Informatics Researchers in South Africa. 14th International Conference on Social Implications of Computers in Developing Countries (ICT4D), May 2017, Yogyakarta, Indonesia. pp.280-291, 10.1007/978-3-319-59111-7_24. hal-01650119

\section{HAL Id: hal-01650119 \\ https://hal.inria.fr/hal-01650119}

Submitted on 28 Nov 2017

HAL is a multi-disciplinary open access archive for the deposit and dissemination of scientific research documents, whether they are published or not. The documents may come from teaching and research institutions in France or abroad, or from public or private research centers.
L'archive ouverte pluridisciplinaire HAL, est destinée au dépôt et à la diffusion de documents scientifiques de niveau recherche, publiés ou non, émanant des établissements d'enseignement et de recherche français ou étrangers, des laboratoires publics ou privés. 


\title{
Social Mapping for Communal Sensemaking: the case of Development Informatics Researchers in South Africa
}

\author{
Judy van Biljon ${ }^{1, *}$ and Mario Marais ${ }^{2}$ \\ ${ }^{1}$ University of South Africa, Johannesburg, South Africa \\ vbiljja@unisa.ac.za \\ ${ }^{2}$ CSIR Meraka Institute, Pretoria, South Africa \\ mmaraisecsir.co.za
}

\begin{abstract}
The community dynamics revolve around shared interests, norms, and identities. The sustainable exchange of resources for development is only possible if the members of the community are connected and the collaboration opportunities and practices are well-understood. This work in progress paper proposes social mapping as an innovative way of making sense of the connections between Development Informatics researchers towards understanding the research landscape and behavioural collaboration patterns. The data set includes the associations, collaborations and publication connections of at least 50 South African researchers. The maps were constructed using the Kumu social mapping tool. The results show that social mapping has the potential for presenting research connections visually in a way that supports sensemaking of the social dynamics within the society by considering the structural and behavioural patterns. The findings are limited by the fact that any attempt at representing the members of a dynamic community is seldom up to date and never complete. That limitation is managed by rigorously specifying the data capturing process and period. Furthermore, sensemaking theory informs that human sensemaking implicitly involves the unmaking of sense to adjust to time-space gaps. The contribution is a description and demonstration of how social mapping technology can be used to display information towards making sense of a research community.
\end{abstract}

Keywords: Communal sense-making, social mapping, social dynamics, development informatics

\section{Introduction}

Participatory Community mapping as a sociotechnical innovation integrates the oldest social institution of human kind with the newest frontiers of material society through the joining and convergence of community with information sciences and technologies [1]. Research communities co-exist in a complex context of relations and interactions with other communities, supported by a multi-layered technical infrastructure. 
To improve their collaboration, community members and network stakeholders need to continually make sense of it [2]. The Development Informatics (DI) community experience collaboration challenges due to the multi- and transdisciplinary nature which necessitates sharing knowledge from dissimilar disciplines [3]. The diversity in the stakeholders, which include researchers, funding agencies, government departments, participants and practitioners from the developing, emerging and developed economies introduce further complexities in knowledge management and knowledge sharing [4].

This knowledge management complexity underlie the challenge of building on existing knowledge towards research standards, methodologies and theories [3,5] and agreement on how research quality can be ensured $[6,7,8]$. Community building can also aim at building social capital. Research on the social capital of rural ICT entrepreneurs has shown that the very fact of seeing oneself as part of a network has a positive effect [9].

Community-building is an iterative process in which community members increasingly become aware of what binds them, the increased level of awareness can inform and trigger new community building activities [10]. According to Rey-Moreno, Miliza, Mweetwa, van Stam, \& Johnson [11] the main opportunities of wireless Community Networks lie in the engagement of community members and the provisioning of a space for their development, in the community, for the community.

In the multi-, inter- and transdisciplinary research areas such as DI research, there are researchers from related fields as well as stakeholders interested in getting a quick overview of the research landscape of the DI community. The need involves basic information in response to questions like, who are the DI researchers, which institutions are they affiliated with and what are their fields of specialisation? In addition, tacit knowledge is required to answer questions such as how do DI researchers disseminate their research (considering conferences and journals), who do they collaborate with and why? This tacit knowledge is not available to novice researchers or international researchers without access to a South African DI champion.

Tacit knowledge poses a major challenge to $\mathrm{KM}$ as expertise and reasoning processes are difficult for individuals to articulate [4]. Communities of practice [12] play an important role as tacit knowledge is used and shared by the participants in social learning processes to identify appropriate actions to deal with shared challenges. Formalization of sensemaking efforts help to reduce ambiguity and to create common foundations for collaborative action [13]. A core communal sensemaking activity is community mapping. Originally started as a cartographic exercise to map the geographical connections and common ground that local communities share, community mapping is also being used for providing visualizations of argumentation and conversations [14]. Communal sensemaking aids technology enabled development. For example, the use of communication and mapping technology to connect individuals in geographical communities that live in the same area, but live separate lives and have individual experiences of the various and often uncoordinated development interventions. In the DI field it can break down the boundaries between the disciplines of researchers (e.g. computer science, geography, development studies, community development) and the boundaries between researchers and implementing bodies such as 
non-governmental organizations (NGOs) to create a space to support sensemaking. Going beyond the academic community it can drive coordination of development and other investments in a community from the bottom-up. In SA this is a major need of the Department of Rural Development and Land Reform [15] as evidenced at the five week strategy session in Sept/Oct 2016.

The purpose of this paper is to explore the use of social mapping towards representing collaboration in a research area by considering the case of South African Development Informatics research. Abiding by the programming mantra: ' Eat your own dogfood", we as DI researchers aim to investigate social community mapping technology for mapping the South African DI community. Geographical community mapping methods stress strong community participation in the map making process. Therefore we continually document the social mapping process and engage the community for consent, peer-review and feed-back. We outline the approach being developed; present initial results of applying social mapping in the case of the South African DI community, and reflect on the lessons learned in this community mapping exploration.

\section{Knowledge management and sensemaking for Participatory Community mapping}

The literature review covers knowledge management, the design of knowledge repositories in ICT4D and the use of social mapping in supporting knowledge management and sensemaking.

\subsection{Knowledge management and sensemaking}

The objective of a Knowledge Management (KM) is to support the construction, sharing and application of knowledge in organizations [16]. This means that the KM activities consists of the administration of knowledge assets of an organization and the sharing and enlargement of those assets [17]. The terms knowledge transfer and knowledge sharing have not been well-distinguished. According to Paulin and Suneson [18] authors who use the term knowledge transfer tend towards the objectivist perspective of knowledge while knowledge sharing is used with a more subjective perspective i.e. sharing via synchronous or asynchronous conversations and communications between people. The effectiveness of IT artefacts can be demonstrated through knowledge sharing activities [19]; conversely these activities can generate valuable insight in improving knowledge sharing towards supporting communication and ensuring a solid foundation for collaboration.

The human need to make sense of their experience in the world underlies much of this activity which has been defined as sensemaking [20]. The sense-making approach to studying and understanding users and designing systems to serve their needs has been developed in the fields of communication, library and information science but it has wider implication also for knowledge management [21]. Sensemaking and unmaking is a mandate of the human condition. The theoretical assumptions of the theo- 
ry are based on the metaphor of situation-gap-uses that has been validated in numerous empirical studies [22]. Sense making departs from the premise that humans live in a world of gaps: a reality that changes across time and space which involves, at least in part a gap in any given time-space. Primary emphasis is placed on moving conceptualizations of users, information and reality from the noun-based knowledge-as-map frameworks of the past to verb based frameworks emphasizing diversity, complexity and sense-making potentials. The core sense making assumptions is the idea that knowledge made today is rarely perfectly suited to application tomorrow and in some cases becomes tomorrow's gap. In this view, attending to the unmaking of sense is as important as attending to its making. Fundamental to this study is sensemaking as a mechanism towards turning circumstances into a situation that is comprehended explicitly in words and that serves as a springboard for action [23]. The concepts of making and unmaking sense are critical in defending the usefulness of an incomplete and even incorrect knowledge representation (considering the time-space domain). Knowledge management in the ICT4D space will now be considered.

\subsection{ICT4D Knowledge repositories}

Knowledge management systems used in the ICT4D context are known by different names including e-portals, online knowledge repositories and knowledge sharing platforms (KSPs). All of these systems are essentially Web based collections of information providing varying degrees of access and interaction but there are critical differences between what knowledge is made available, the target audience, the access and the interactions [24]. KM is recommended as part of any DI project to optimize its probability of success specifically by sustaining and growing a user community of practice $[4,25]$. The provision of a social map also makes a practical contribution to development by creating an awareness of the social infrastructure that accompanies the technological infrastructure and the need to adopt a socio-technical systems (STS) view [26]. In this research the social mapping is part of a bigger goal, namely to create an open knowledge repository which supports identification of relevant research and possible collaborations, discussions and the formation of communities of practice to share information such as: research agendas, funding opportunities, publication opportunities, methodologies, theories, models and frameworks with the wider DI community including practitioners, government and NGOs. KM requirements need to continually adapt to fit the needs of the intervention. In the context of ICT4D the nature of the intervention has changed over time and Heeks [27] refers to phase ICT4D 0.0 (use of computers in the economy), 1.0 (ICT as development tool - telecentres) and 2.0 (ICT as the transformative platform for development). Participation to foster innovation is key and Heeks (ibid.) refers to innovation strategies as being pro-poor (for the poor), para-poor (working with the poor) and per-poor (innovation by the poor in their communities). In an ICT4D 1.0 approach, KM can be applied to sustain technology support and maintenance without the aid of the original development team [4] or remote experts [28]. An example of ICT4D 2.0 para-poor innovation is the development of a pharmacy system for antiretroviral drug dispensing in South African public health clinics [29]. The research and development team adopted the 
concept of Open Development [30] which emphasizes universal access to information, collaborative participation in knowledge creation and diversity of knowledge systems. In this approach Louden and Rivett [29] contend that communities of practice may be the route to "actionable knowledge" [31] that is developed and sustained after the end of research processes and projects. In the broad DI context there are multiple stakeholder communities including beneficiaries, practitioners, academia, government, civil society (e.g. NGOs) and private sector organisations. The diversity of the target audience for a knowledge management endeavour is challenging if an open access environment is planned. For example, academics may seek examiners, reviewers and collaborators, while funding agencies and NGOs may seek research experts in a specific field. Students and novice researchers may seek links to reputable sites and research opportunities. The community context influences the nature of the formal and informal knowledge production processes and the tools that need to be supported. Wenger, White and Smith [12] advocate for the use a range of tools and platforms to support communities of practice. Considering the dimensions in Figure 1, participatory community social mapping can be described as informal sharing with each other and hence fits in the upper right hand quadrant. Social mapping is an example of what Wenger calls "Building shared understanding (3)" and also provides a means of "Producing assets (4)".

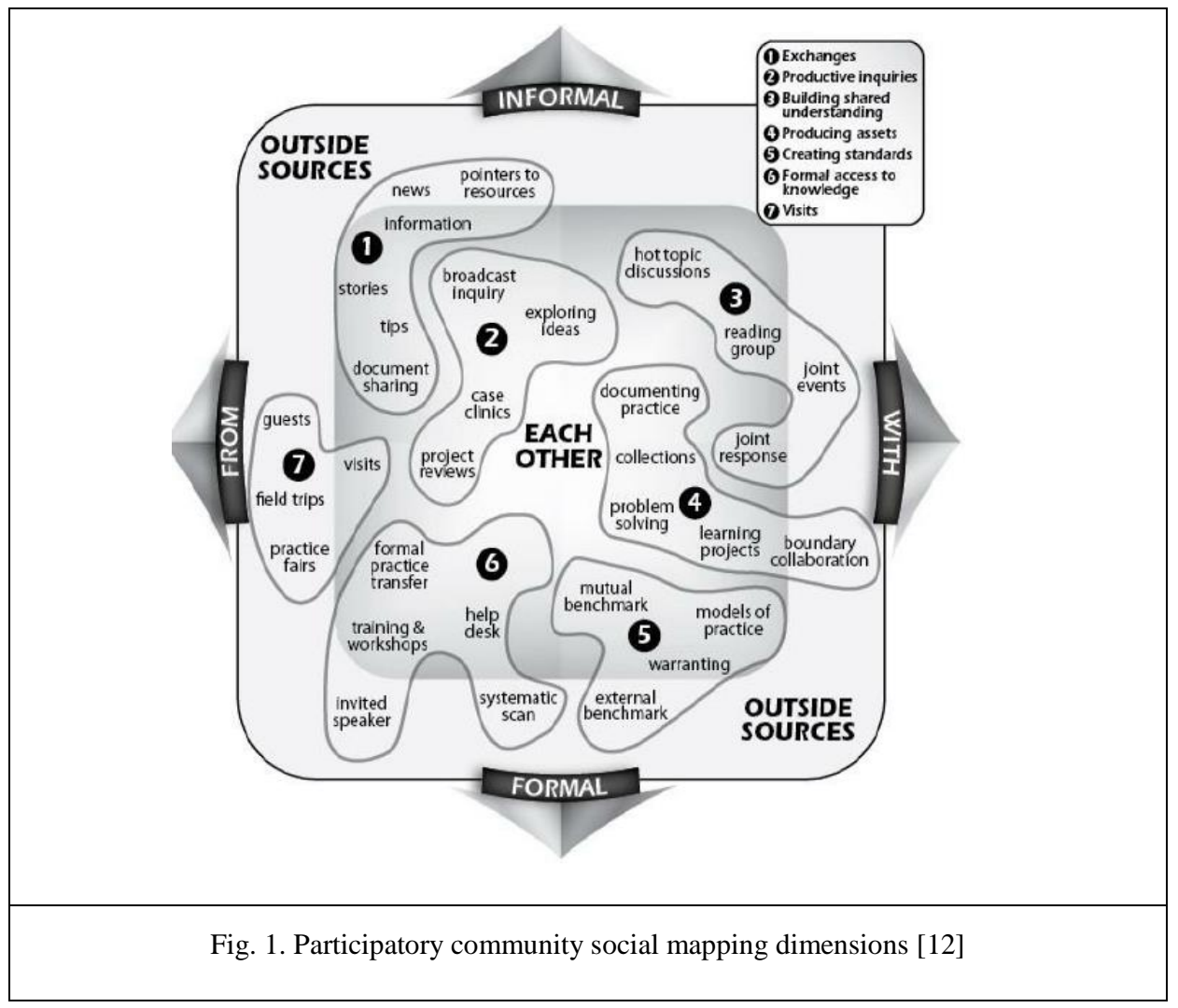




\section{Research Design}

The community was defined as Development Informatics or ICT4D researchers in South Africa. They were identified by doing a Google Scholar search using the terms "Development Informatics" or "ICT4D" and 'South Africa'. The search was carried out during September 2016. The search returned 66 names and those were contacted for consent to use their research profile information. Consequently 52 replied, 51 positively and one declined. The following information categories were then added to a spreadsheet for the researchers who consented: their affiliations (institution where they were employed), the conference proceedings published in, the journals published in and the domains sub-field(s) of DI or related field that they were involved in. A total of 16 institutions were added which include universities and other research institutions such as the Council for Industrial and Scientific Research (CSIR). The researchers had published in 24 conferences' proceedings and in 38 different journals.

We acknowledge the limitations on correctness (in terms of being up-to date) and completeness of the data. Despite our best efforts and intentions of diligently capturing all the ICT4D and Development Informatics researchers the process described is prone to human error with the result that not all the researchers have been included. The next step would be to periodically present the map to the community for feedback and then update it to improve the accuracy.

\subsection{The mapping language}

The mapping language needs to distinguish between elements (depicting sociotechnical concepts of the community network) and connections (representing relations and interactions between those elements). Informed by the participatory community mapping knowledge structure proposed by De Moor [10] the following was constructed in terms of elements and connections. The following elements have been identified:

- Participants including Persons; Institutions; Conferences; Journals and Domains

- Activities (Activities are outcomes as well, but being processes, they can also generate other processes and results and are a direct source of community building). These include events, funding proposals and calls for papers.

- Results (tangible static results like publications)

- Tools that can be used to support activities like physical Meetings (e.g. "Annual Meetings", "Network Meetings", "Presentations", "Conferences") or online tools (e.g. participant websites, social media such as project apps, Twitter, Facebook).

Regarding connections, communities are networks of relationships and interactions for mutual benefit. A conceptual model of community consists of collective identity, local participation, and diverse support networks [10]. Carrol [32] mentions four composite variables for community membership and participation, namely: Belonging (identity), Informedness (passive participation), Activism (active participation), and Associations (support networks). De Moor [10] built on this approach to identify four types of connections, ordered in increasing degree of participant involvement: 
- Informedness (being informed about activities of the community, but not being part of it).

- Associations (being an explicit member of the community in the sense of having made a commitment to participate)

- Participation (actual participation in the activities of the community)

- Producing (producing visible, measurable results as outcomes of the activities). This is the most involved kind of participation).

Given our approach to data capturing (as explained above) all the researchers had published papers which places them on the fourth level, namely that of producing. Extending the data set to reflect the member participating (without having published) may be advisable but there lies the challenge of balancing completeness with focus - a challenge to be explored in further research. The map making has been done by the authors with the help of three research assistants to capture and validate the data and manage the researchers. Ideally, community managers or members should be involved and be trained to become map makers but given the complexity of the mapping language, tool, and process that may not be feasible, also in terms of the time and effort required. De Moor [10] also distinguished various levels of map making literacy including the overall structure, layout, and functionality of a community map which could be created by a "master map maker". Selected community managers or members could be trained to expand the partial "domain maps". A map of a dynamically evolving community is never complete and there is always a trade-off between completeness and feasibility. For researchers as community members, the main reason to contribute to and use the map is to improve the bigger picture in terms of correctness and completeness and to ensure that their participation as researchers is represented accurately. In summary, the researchers were abstracted as the object type person, together with institution, conference; journal and research domain as object types. The connections affiliation (between person and institution), publish (between person and conference and also between person and journal), as well as research domain between (domain and person) were then added to the connections table. The findings are limited by the incomplete nature of any map of a dynamic community. Furthermore the publication data was captured from the Internet using Google Scholar; using another search engine may provide different information. The next step will be to present the map to the researchers to give feedback on the map and update their information, thereby creating an updated map which will be shared with the wider DI community.

\section{$4 \quad$ Results}

Figures 2 and 3 are examples of how the information about the community can be depicted to support sensemaking of the elements and connections. Figure 2 focuses on the institutions and provide some indication of the number of researchers affiliated to the institutions. The data capturing procedure is limited by the visibility and discoverability of the individual researcher's so it does not claim to provide a complete picture merely the starting point of a map that needs to be completed. 


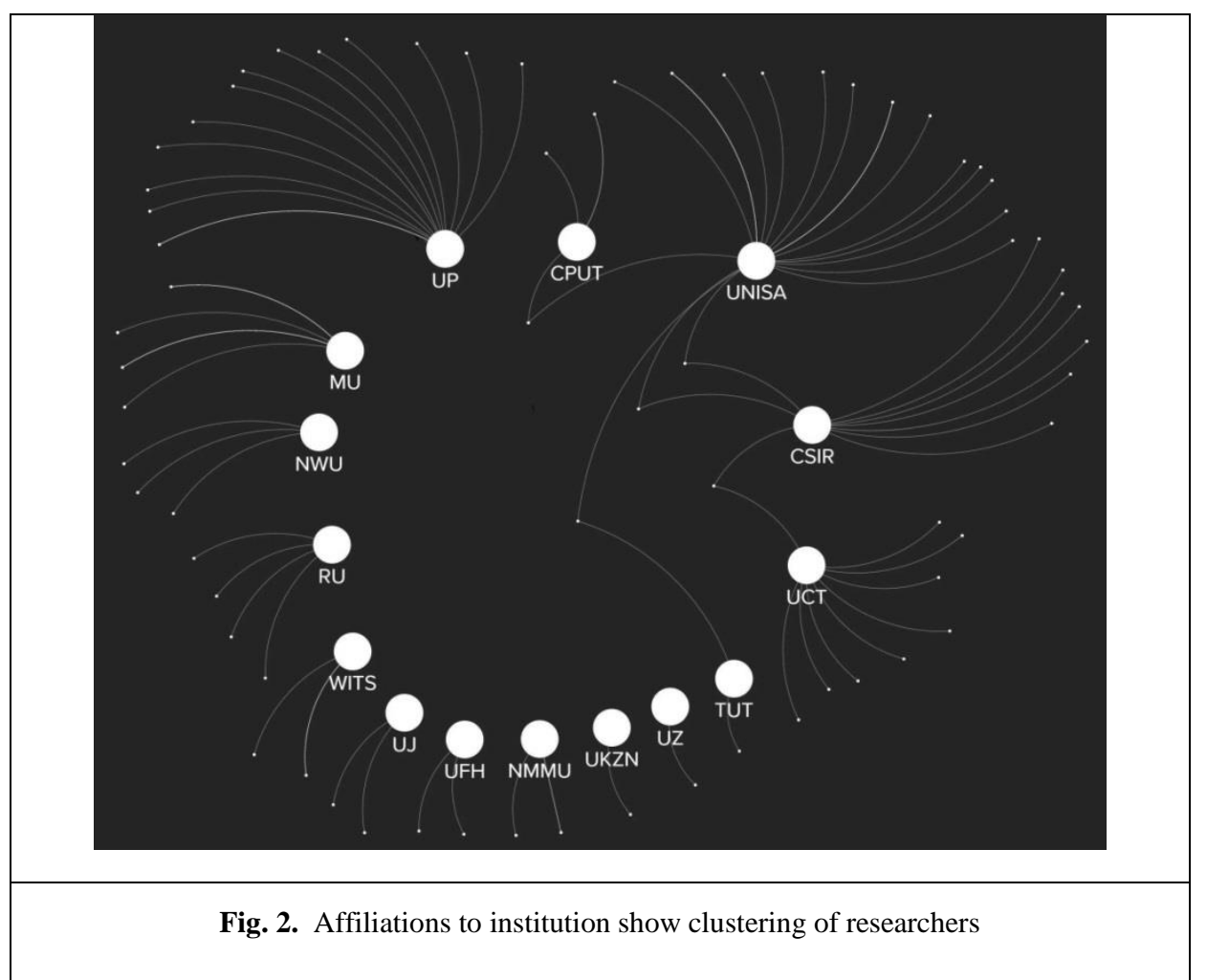

The following abbreviations were used: University of Pretoria (UP). Council for Scientific and Industrial Research (CSIR), Cape Peninsula University of Technology (CPUT), University of South Africa (Unisa), University of KwaZulu Natal (UKZN), University of Cape Town (UCT), University of Pretoria (UP), University of Johannesburg (UJ), University of Zululand (UZ), Tshwane University of Technology (TUT), Rhodes University (RU), Monash University (MU), North-West University (NWU), Nelson Mandela Metropolitan University (NMMU), University of Fort Hare (UFH) and the University of Witwatersrand (WITS).

Considering Figure 2, the results highlight that four institutions dominate in terms of the number of researchers (UP, UCT, CSIR and Unisa) with a cluster of eight or more researchers, followed by four institutions with three or more researchers (CPUT, RU, NWU and MU). There are only five researchers with formal relationships with more than one university and all but one of these relationships is with Unisa. The data is based on institutional affiliations reported in publications so it would show an affiliation even when the researcher had left the institution. The advantages of having an up-to-date map has to weighed against building a history of how the community evolved; at this stage the creation of a history seems more helpful towards sensemaking. Figure 3 depicts the conferences attended by South African researchers in this sample. 


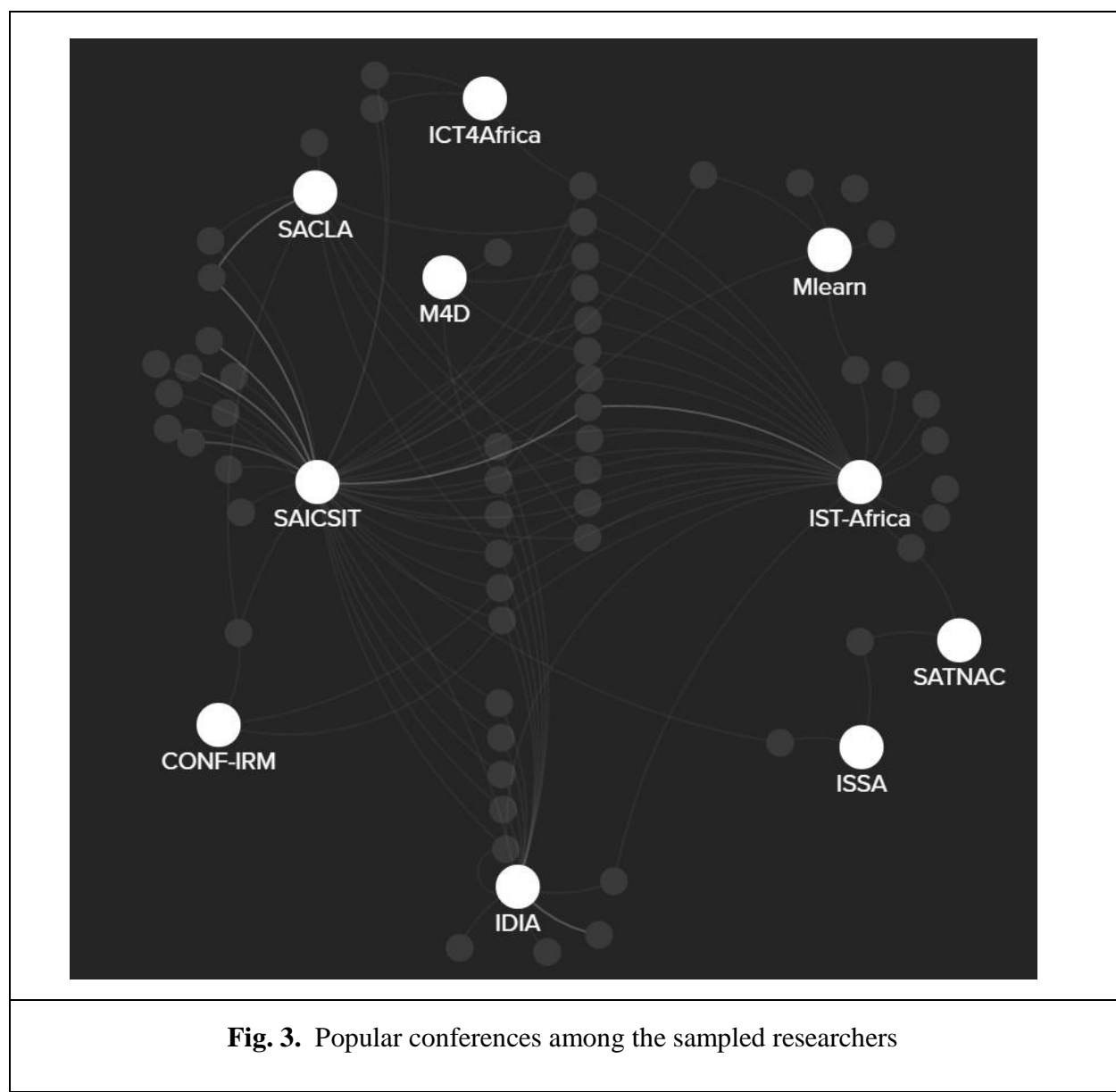

South African and African conferences have the most attendees but an international conference like CONF_IRM features prominently since it was recently hosted in Cape Town, South Africa. The SAICSIT (62), IST-Africa (31) and IDIA (21) conferences had the most attendees and many attendees attended both or all three of these conferences. Six had attended all three conferences. Twelve researchers had attended SAICSIT and IST-Africa which are conferences that are hosted in Africa. Five had attended SAICSIT and the IDIA, which is an international conference that is held mostly in the Global South. IDIA is organised by Monash University South Africa (MU) and hence has a strong South African link. The importance of research regarding mobile device use is reflected in the attendance of the M4D and the Mlearn conferences and indicates the size of this particular research community. This overview of the conferences that researchers had attended could be valuable to novice researchers when planning submissions. Due to space limitations the connection between researchers and research domains had to be omitted but that is important in determining the active research fields, the researchers working in these fields, the relationships between the researchers and their relationships with researchers in related fields. 


\section{Discussion}

Despite the acknowledged limitations and the reduced scope of the mapping, the community maps representing researchers' links to institutions and conferences respectively proved useful in identifying behaviours that would be more difficult to observe from textual information. The information was displayed as noun-based knowledge-as-map frameworks but once these have been presented to the community for feedback and refinement, future research will look into verb based frameworks for improving diversity, complexity and sense-making potential. Qualitative research involving interviews and focus groups with different stakeholder is necessary to improve the quality and depth of the representation and to extend this to stakeholders beyond the academic research community.

The selection decisions, including the point of departure and selection criteria for researchers, how to filter the data and how to disseminate the results to the community without inadvertently disadvantaging a person or entity by omission or inaccuracy resonate with the sensemaking challenges of conceptualizing knowledge making. Furthermore, as Dervin [21]:45 advises, sensemaking "mandates attentions to ways of bracketing or taming at least in part the impacts of power which constrain human willingness to share and problem solve collaboratively". Presenting this study for peer-review and scrutiny through continuous publication is one of the initiatives in the drive for accountability and transparency towards a fair, unbiased representation of the South African Development Informatics community. Besides the theoretical contributing towards highlighting the knowledge management challenges, the community mapping artefact of a specific community also has practical use. An example is the use by local communities of participatory social mapping to provide comprehensive information to government departments regarding the coordination, alignment and duplication of development initiatives [20].

\section{Conclusion}

This paper outlined preliminary work on a participatory, community mapping project piloted for South African DI researchers. Initial findings show potential for mapping the evolution of the community towards creating some history of involvements as well as the status quo. A moral challenge for community mapping is ensuring that everyone can participate in and benefit from the innovation. This raises questions about how much the communities can realistically be involved and finding a balance between making the information accessible and as accurate as possible on the one hand and not inconveniencing the community with constant requests on the other. More research is required to extend the scope to include the other stakeholders in ICT4D and also to optimise the selection criteria for data capturing towards presenting the dynamics of benefit to the community. The mapping component will be integrated into the South African Development Informatics \& ICT4D Platform (SADIIP) which will increase the visibility and usefulness for the wider community. 


\section{$7 \quad$ Acknowledgement}

This work is based on the research supported by the South African Research Chairs Initiative of the Department of Science and Technology and National Research Foundation of South Africa (Grant No 98564). We also acknowledge all the South African researchers who responded to our communication.

\section{$8 \quad$ References}

[1] J. M. Carroll, P. C. Shih, and J. Kropczynski, "Community Informatics as Innovation in Sociotechnical Infrastructures," J. Community Informatics, vol. 11, no. 2, 2015.

[2] A. De Moor, "Communities in context: Towards taking control of their tools in common(s)," J. Community Informatics, vol. 11, no. 2, pp. 4-9, 2015.

[3] G. Walsham, "Development Informatics in a Changing World: Reflections from ICTD2010/2012," Inf. Technol. Int. Dev., vol. 9, no. 1, pp. 49-54, 2013.

[4] S. Conger, "Knowledge Management for Information and Communications Technologies for Development Programs in South Africa," Inf. Technol. Dev., vol. 1102, no. ahead-of-print, pp. 1-22, 2014.

[5] J. Burrell and K. Toyama, "What Constitutes Good ICTD Research?," Inf. Technol. Int. Dev., vol. 5, no. 3, pp. 82-94, 2009.

[6] G. Walsham, "Are we making a better world with ICTs? Reflections on a future agenda for the IS field," J. Inf. Technol., vol. 27, no. 2, pp. 87-93, 2012.

[7] R. Weber, "Research on ICT for Development: Some Reflections," Proceedings of the 3rd International Development Informatics Conference, Kruger National Park, South Africa, pp. 2-27, 2009.

[8] W. J. Tibben, "Theory Building for ICT4D: Systemizing Case Study Research Using Theory Triangulation," Inf. Technol. Dev., vol. 21, no. 4, pp. 628-652, 2015.

[9] M. A. Marais, "Social capital in the Village Operator model for rural broadband internet access and use.," Unpubl. Dr. Diss. Univ. Pretoria, Pretoria, South Africa, 2016.

[10] A. De Moor, "Towards a participatory community mapping method: the Tilburg urban farming community case," Adjun. Proc. Communities Technol. Conf., vol. 12, p. 11, 2015.

[11] C. Rey-Moreno, J. Miliza, F. Mweetwa, G. van Stam, and D. L. Johnson, "Community Networks in the African Context: Opportunities and barriers," AfriCHI, pp. 237-241, 2016.

[12] J. D. Wenger, E., White, N., Smith, Digital Habitats: Stewarding technology for communities. Portland: CPsquare, 2009.

[13] P. W. L. Vlaar, F. A. J. Van den Bosch, and H. W. Volberda, "Coping with Problems of Understanding in Interorganizational Relationships: Using Formalization as a Means to Make Sense," Organ. Stud., vol. 27, no. 11, pp. 
1617-1638, 2006.

[14] A. Okada, S. Buckingham, and T. Sherborne, Knowledge Cartography: Software tools and mapping techniques. London, UK: Springer, 2008.

[15] M. A. Marais, "Researcher notes. Phakisa workshop of the Department of Agriculture, Forestry and Fisheries with the Department of Rural Development and Land Reform," Kemptonpark, Johannesburg, 2016.

[16] D. Leidner, "Knowledge management and knowledge management systems," J. Strateg. Inf. Syst., vol. 9, no. 2-3, pp. 101-105, 2000.

[17] M. Ben Chouikha and S. Dakhli, "The Dimensions of Knowledge Sharing," MCIS 2012 Proceedings, 2012.

[18] D. Paulin and K. Suneson, "Knowledge Transfer, Knowledge Sharing and Knowledge Barriers - Three Blurry Terms in KM," Electron. J. Knowl. Manag., vol. 10, no. 1, pp. 81-91, 2012.

[19] T. Li, "The Interplay between Knowledge Sharing and IT Artifacts in the Working Contexts," in Twenty-second Americas Conference on Information Systems, San Diego, 2016.

[20] G. Klein, B. Moon, and R. F. Hoffman, "Making sense of sensemaking: alternative perspectives," IEEE Intell. Syst., vol. 21, no. 4, pp. 70-73, 2006.

[21] B. Dervin, "Sense-making theory and practice:an overview of user interests in knowledge seeking and use," J. Knowl. Manag., vol. 2, no. 2, pp. 36-46, 1998.

[22] R. Savolainen, "The sense-making theory: Reviewing the interests of a usercentered approach to information seeking and use," Inf. Process. Manag., vol. 29, no. 1, pp. 13-28, 1993.

[23] K. E. Weick, K. M. Sutcliffe, and D. Obstfeld, "Organizing and the Process of Sensemaking," Organ. Sci., vol. 16, no. 4, pp. 409-421, 2005.

[24] G. Mosweunyane and L. A. Carr, "Direct desktop-repository deposits with SWORD," in 2014 IST-Africa Conference Proceedings, 2014.

[25] J. P. Singh and M. Flyverbom, "Representing participation in ICT4D projects," Telecomm. Policy, vol. 40, no. 7, pp. 692-703, 2016.

[26] B. Whitworth and A. De Moor, Handbook of Research on Socio-Technical Design and Social Networking Systems. New York: IGI Global, 2009.

[27] R. Heeks, "ICT4D 2.0: The next phase of applying ICT for international development," Computer, IEEE, vol. 41, no. 6, pp. 26-31, 2008.

[28] M. Geldof, D. J. Grimshaw, D. Kleine, and T. Unwin, "What are the key lessons of ICT4D partnerships for poverty reduction?," 2011.

[29] M. Loudon and U. Rivett, "Enacting Openness in ICT4D Research," Inf. Technol. Int. Dev., vol. 7, no. 1, pp. 33-46, 2011.

[30] M. L. Smith and L. Elder, "Open ICT ecosystems transforming the developing world," Inf. Technol. Int. Dev., vol. 6, no. 1, pp. 65-71, 2010.

[31] G. Hearn and M. Foth, "Action research in the design of new media and ICT systems," in Topical issues in communications and media research. New York: Nova Science, pp. 79-94, 2005.

[32] J. M. Carroll, The Neighborhood in the Internet: Design Research Projects in Community Informatics,. New York: 1st ed., Routledge, 2012. 